\title{
Atrial septostomy and disease targeting therapy in pulmonary hypertension secondary to neurofibromatosis
}

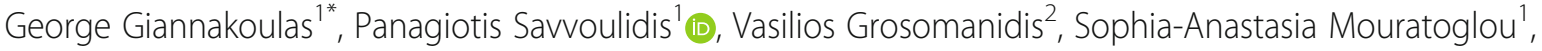 \\ Haralambos Karvounis ${ }^{1}$ and Stavros Hadjimiltiades ${ }^{1}$
}

\begin{abstract}
Background: Neurofibromatosis type 1 (NF1) is a rare multisystem genetic disorder. During the course of the disease it can be rarely complicated with pulmonary hypertension $(\mathrm{PH})$ which confers a dismal prognosis.

Case presentation: We describe the case of a 57-year-old female patient with NF1 complicated by severe precapillary PH despite dual disease-specific oral combination therapy. The patient was treated with initial atrial septostomy followed by administration of high-dose subcutaneous treprostinil with a favorable medium-term clinical and hemodynamic response.
\end{abstract}

Conclusions: PH secondary to NF1 may be successfully treated with the combination of atrial septostomy and PH targeted therapy in selected patients.

Keywords: Neurofibromatosis, Pulmonary hypertension, Septostomy, Case report

\section{Background}

Neurofibromatosis type 1 (NF1) is a genetic disease with a prevalence of 1:3500 in the general population, transmitted with the autosomal dominant inheritance pattern and with full penetrance characterized by prominent skin features (hyperpigmented macules, termed café-au-lait spots and nerve tumors), optical tumors and other central nervous system tumors, certain bony abnormalities, some learning deficits and an increased risk of certain non-nervous system cancers [1]. Mutations of the NF1 gene, which encodes neurofibromin and is located at chromosome 17q11.2, a negative regulator of the ras signal transduction pathway that has a role in both tumor suppression and regulation of cell growth and proliferation, are responsible for the NF1 [2].

A rare still morbid complication of NF1 is pulmonary hypertension $(\mathrm{PH})$ which confers a dismal prognosis overall. To the best of our knowledge this is the first

\footnotetext{
* Correspondence: giannak@med.auth.gr

'Department of Cardiology, AHEPA University Hospital, Aristotle University of

Thessaloniki, Stilp. Kiriakidi 1, Thessaloniki 54637, Greece

Full list of author information is available at the end of the article
}

documented report of successful treatment of PH secondary to NF1 with atrial septostomy followed by escalation of $\mathrm{PH}$ targeted treatment.

\section{Case presentation}

A 57-year-old female patient with a history of NF1 and PH initially diagnosed 3 years ago, already on conventional treatment with supplemental oxygen and anticoagulation, as well as disease-specific double oral combination therapy (ambrisentan $10 \mathrm{mg}$ od and tadalafil $40 \mathrm{mg}$ od) was admitted to the hospital because of worsening dyspnea on mild exertion and a presyncopal episode.

Her past medical history was notable for surgically repaired pyloric stenosis and 2 abortions during the third trimester of gestation due to intrauterine fetal death, followed by a successful pregnancy. The patient had already undergone an extensive workup which excluded known causes of $\mathrm{PH}$. Lung ventilation/perfusion scan was not suggestive for chronic thromboembolic disease and high-resolution CT of the lungs was negative for interstitial lung disease. Blood tests excluded other causes of pulmonary hypertension. 
Considering the patient's clinical deterioration, the decision was made to proceed immediately with atrial septostomy, due to inherent difficulties in the reimbursement of prostanoids in our hospital at that time. The patient had an uneventful procedure with graded balloon dilation of the interatrial septum with gradually increasing inflated balloons diameter of 6,8 and $10 \mathrm{~mm}$. A moderate decrease in right atrial pressure (Fig. 1), a mild increase in cardiac index and, as expected, a decrease in $\mathrm{SaO} 2$ was noted (Table 1) due to the right-to-left shunting through the atrial septum. The patient remained clinically and hemodynamically stable and was discharged a few days later.

After an initial modest improvement in symptoms, six-minute walk test (6MWT) and NT-proBNP at 2 months, access to prostanoids was eventually gained and the patient was started on subcutaneous treprostinil with gradual increase in the administered dose up to $100 \mathrm{ng} / \mathrm{kg} / \mathrm{min}$ in a time period of 7 months.

The patient during a follow-up period of 2 years demonstrated gradual improvement and at present remains in World Health Organization class 2 with significant hemodynamic improvement (Table 1). A recent transthoracic echocardiogram demonstrated the positive remodeling of the right ventricle (Fig. 2a, b) and the persistence of the atrial septostomy (Fig. 2c). The shunt flow was small and at rest was from the left atrium to the right atrium but after $2 \mathrm{~min}$ of isometric exercise (hand grip and feet in cycling position) the shunt became right-to-left (Fig. 2d).

\section{Discussion}

A few cases suggesting an association of NF1 gene mutation and precapillary $\mathrm{PH}$ have been published $[3,4]$. Plexiform lesions similar to those observed in human idiopathic $\mathrm{PAH}$ have been described, implying that vasculopathy of neurofibromatosis might underlie the pathophysiology of $\mathrm{PH}$, a severe complication, which seems to show a predilection for women with severe clinical and hemodynamic impairment and a poor outcome [5].

Herein, we report a case of a patient with NF1 and severe precapillary $\mathrm{PH}$, without parenchymal lung disease, yet with prominent pulmonary vascular involvement, treated with atrial septostomy, followed by the administration of subcutaneous treprostinil. The medium-term clinical response after 2 years was impressive with improvement in her functional class, 6MWT distance, hemodynamic parameters and NT-proBNP. To the best of our knowledge this is the first published case of $\mathrm{PH}$ secondary to neurofibromatosis treated successfully with the combination of atrial septostomy and aggressive $\mathrm{PH}$ targeted therapy.

The favorable clinical response of our patient to the atrial septostomy and the further gradual, but more pronounced, improvement with the chronic administration of subcutaneous treprostinil suggests that pulmonary vasculopathy is the underlying mechanism of $\mathrm{PH}$ in these patients. The creation of a shunt that decreases the preload of the right ventricle and increases that of the left ventricle with concomitant increase in the cardiac output makes it easier to initiate and uptitrate the prostanoid infusion. The long-term effect of the persistence of the

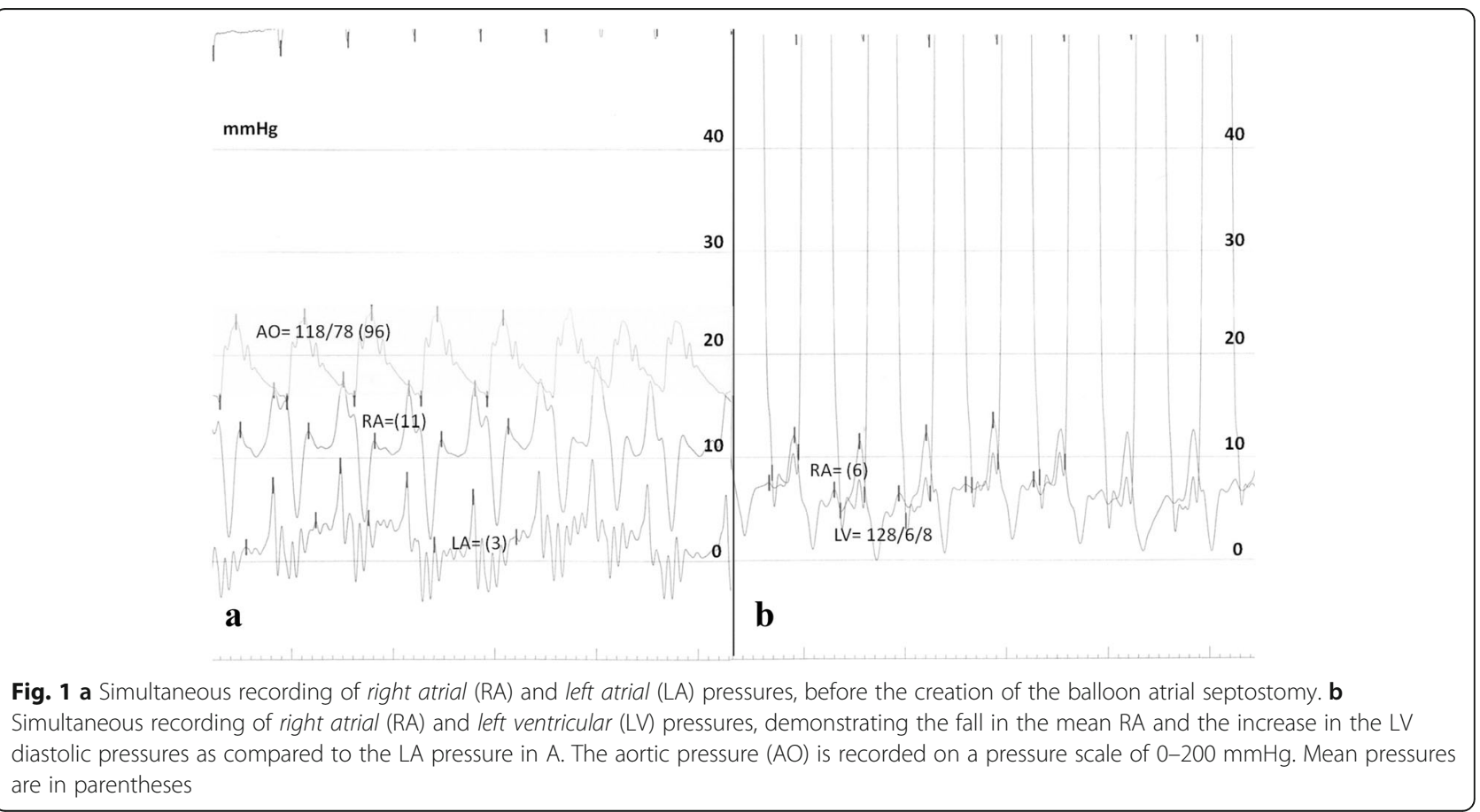


Table 1 Serial hemodynamic, functional and neurohormonal measurements

\begin{tabular}{|c|c|c|c|c|c|}
\hline Parameter & Jan 2011 & $\begin{array}{l}\text { PreBAS } \\
\text { Mar } 2014\end{array}$ & PostBAS & $\begin{array}{l}\text { Trepostinil } \\
\text { Mar } 2015\end{array}$ & $\begin{array}{l}\text { Trepostinil } \\
\text { Feb } 2016\end{array}$ \\
\hline HR (beats/min) & 76 & 91 & 90 & 71 & 70 \\
\hline RAP $(\mathrm{mmHg})$ & (3) & (11) & (7) & (4) & (6) \\
\hline PAP $(m m H g)$ & 68/26 (43) & 130/57 (84) & 135/56 (84) & 106/36 (63) & 77/30 (49) \\
\hline $\begin{array}{l}\text { PAWP/LAP* } \\
(\mathrm{mmHg})\end{array}$ & (6) & $(2)^{*}$ & $(7)^{*}$ & (7) & $(9)^{*}$ \\
\hline Ao $(\mathrm{mmHg})$ & 130/68 (93) & 122/65 (84) & 124/65 (84) & 119/71 (87) & 128/65 (85) \\
\hline PVR (WU) & 8.3 & 27.1 & 26.3 & 11.6 & 6.8 \\
\hline $\mathrm{Cl}\left(1 / \mathrm{min} / \mathrm{m}^{2}\right)$ & 2.9 & 1.9 & 2.0 & 3.1 & 3.7 \\
\hline $\mathrm{SaO} 2$ (\%) & $\begin{array}{l}97 \text { at rest } \\
90 \text { (during exercise) }\end{array}$ & 98 & 93 & $\begin{array}{l}95 \text { at rest } \\
\text { (70 during exercise) }\end{array}$ & $\begin{array}{l}98 \text { at rest } \\
\text { ( } 75 \text { during exercise) }\end{array}$ \\
\hline 6MWT (m) & 489 & $230^{\mathrm{a}}$ & $335^{b}$ & 345 & 399 \\
\hline NT-proBNP (pg/ml) & 125 & $3402^{\mathrm{a}}$ & $1507^{b}$ & NA & 161 \\
\hline
\end{tabular}

Mean pressures are shown in parentheses

$B A S$ : balloon atrial septostomy, HR: heart rate, RAP: Right atrial pressure, PAP: Pulmonary artery pressure, LAP: Left atrial pressure, $P C W P$ : Pulmonary capillary wedge pressure, Ao: Aortic pressure, PVR: Pulmonary vascular resistance, Cl: Cardiac index, WU: Wood Units, 6MWT: 6-min walking test, NT-proBNP: N-terminal pro-brain

natriuretic peptide, $N A$ : not available

*Asterisk indicates that the pressure was measured in the left atrium

a 2 weeks prior to the procedure

${ }_{1} 1$ month after the procedure

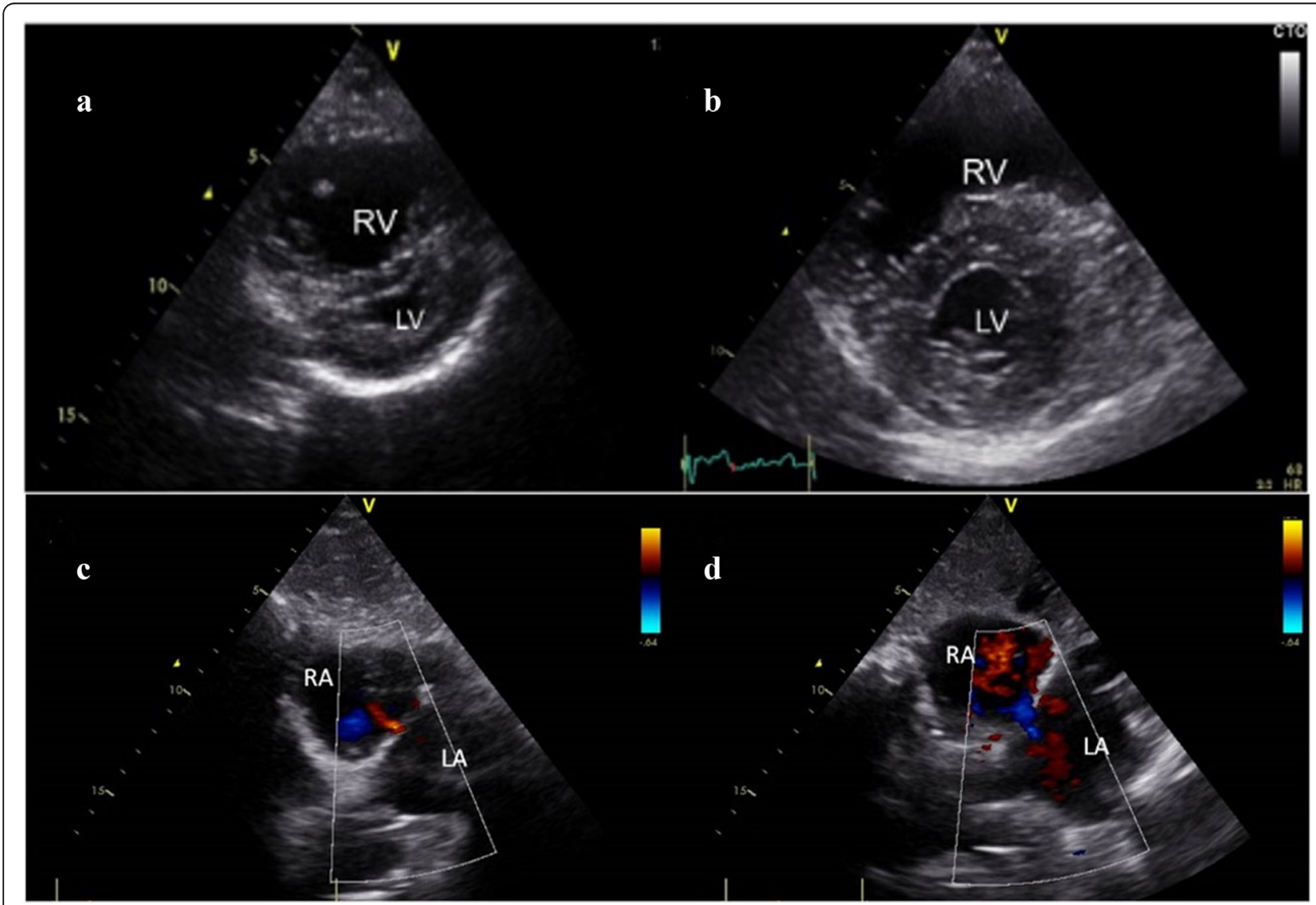

Fig. 2 a, b Short-axis transthoracic echocardiographic view demonstrating the positive remodelling of the right ventricle (RV) 2 years after the atrial septostomy and the initiation of subcutaneous treprostinil. LV = left ventricle c Subxiphoid echocardiographic view of the persistent flow from the left atrium (LA) to the right atrium (RA) at rest $\mathbf{d}$ Reversal of flow from RA to LA after isometric exercise 
shunt in our case, following the decrease in the right sided pressures on chronic treprostinil therapy, is not known; whether the reversal of the shunt during exercise by decreasing the load on the right ventricle will continue to be beneficial, despite the arterial oxygen desaturation, is not clear [6].

There are very few cases in the literature with the utilization of PAH-targeted therapies in these patients [7-9]. Our patient improved significantly after the initiation of treprostinil, while double oral therapy had initially failed. The development of $\mathrm{PH}$ in patients with NF1 confers a dismal prognosis and therefore, the earlier and aggressive treatment with prostanoids should be considered. Finally, listing these patients for lung transplantation is a matter of debate, since a higher than the general population incidence of malignancies has been described [10].

\section{Conclusions}

This report demonstrates the successful management of a patient with PH secondary to NF1 with atrial septostomy in conjunction with PAH targeted therapy. Looking ahead, national and international prospective registries will shed light on the pathophysiology, and especially optimal therapy and prognosis of neurofibromatosisassociated $\mathrm{PH}$ especially in the modern era of targeted $\mathrm{PAH}$ treatment.

\section{Abbreviations}

6MWT: Six minute walk test; NF1: Neurofibromatosis type I; NT-proBNP: Nterminal pro-brain natriuretic peptide; PH: Pulmonary hypertension;

PAH: Pulmonary arterial hypertension

\section{Acknowledgements}

Not applicable.

\section{Funding}

This work was not funded by any grant.

\section{Availability of data and materials}

All the data supporting our findings is contained within the manuscript.

\section{Authors' contributions}

All authors actively participated in the conception, case interpretation and writing of this article. All authors read and approved the final manuscript.

\section{Competing interests}

The authors declare that they have no competing interests.

\section{Consent for publication}

Written informed consent was obtained from the patient for publication of this case report and any accompanying images.

Ethics approval and consent to participate

Ethical approval to report this case was not required.

\section{Author details}

'Department of Cardiology, AHEPA University Hospital, Aristotle University of Thessaloniki, Stilp. Kiriakidi 1, Thessaloniki 54637, Greece. ²Department of Anesthesiology and Intensive Care Medicine, AHEPA University Hospital, Aristotle University of Thessaloniki, Stilp. Kiriakidi 1, Thessaloniki 54637, Greece.

Received: 5 September 2016 Accepted: 24 November 2016
Published online: 07 December 2016

References

1. Korf BR. Malignancy in neurofibromatosis type 1. Oncologist. 2000;5:477-85.

2. Gutmann DH, Collins FS. The neurofibromatosis type 1 gene and its protein product, neurofibromin. Neuron. 1993;10:335-43.

3. Stewart DR, Cogan JD, Kramer MR, et al. Is pulmonary arterial hypertension in neurofibromatosis type 1 secondary to a plexogenic arteriopathy? Chest. 2007;132:798-808.

4. Montani $\mathrm{D}$, Coulet $\mathrm{F}$, Girerd B, et al. Pulmonary hypertension in patients with Neurofibromatosis type 1. Med. 2011:90:201-10

5. Hamilton SJ, Friedman JM. Insights into the pathogenesis of neurofibromatosis 1 vasculopathy. Clin Genet. 2000;58:341-4.

6. Koeken Y, Kuijpers NH, Lumens J, Arts T, Delhaas T. Atrial septostomy benefits severe pulmonary hypertension patients by increase of left ventricular preload reserve. Am J Physiol Heart Circ Physiol. 2012;302:2654-62.

7. Kamdar F, Thenappan T, Missov E. Pulmonary arterial hypertension in von Recklinghausen's disease. Am J Med. 2015;128:39-40.

8. Engel PJ, Baughman RP, Menon SG, Kereiakes DJ, Taylor L, Scott M. Pulmonary hypertension in neurofibromatosis. Am J Cardiol. 2007;99:1177-8.

9. Tamura Y, Ono T, Sano M, Fukuda K, Kataoka M, Satoh T. Favorable effect of sorafenib in a patient with neurofibromatosis-associated pulmonary hypertension. Am J Respir Crit Care Med. 2012;186:291-2.

10. Uusitalo E, Rantanen M, Kallionpää RA, et al. Distinctive cancer associations in patients with neurofibromatosis type I. J Clin Oncol. 2016;34:1978-86.
Submit your next manuscript to BioMed Central and we will help you at every step:

- We accept pre-submission inquiries

- Our selector tool helps you to find the most relevant journal

- We provide round the clock customer support

- Convenient online submission

- Thorough peer review

- Inclusion in PubMed and all major indexing services

- Maximum visibility for your research

Submit your manuscript at www.biomedcentral.com/submit
C Biomed Central 